\title{
OPTICAL ABSORPTION SPECTRA OF TERNARY COMPLEX OF PRASEODYMIUM IN DIFFERENT ENVIRONMENT
}

\author{
ANUP KUMAR GUPTA \\ Department of Physics, Jai Narain Vyas University \\ Jodhpur, Rajasthan, India 342005 \\ anupgupta58@gmail.com \\ SHRI KISHAN UJJWAL ${ }^{2}$ \\ Department of Physics, Jai Narain Vyas University \\ Jodhpur, Rajasthan, India 342005 \\ s.k.ujjwal@gmail.com
}

\begin{abstract}
The optical absorption spectra of complex of Praseodymium in different solvents i.e water, Methanol, Ethanol \& Acetic Acid have been recorded in visible region (360-620 nm for $\operatorname{Pr}^{3+}$ ) using amino acid as primary ligand and diol as secondary ligand. The value of energies \& intensities of various transitions have been calculated using Judd-Ofelt relation is in good agreement with experimental result. The study of complex found it to be covalent in nature. The spectra in visible region have been recorded on model uv-2601 Rayleigh analytical instrument corp.

Keywords: Rare earth metals, Amino acid, Optical absorption Spectroscopy, Judd-Ofelt parameters.
\end{abstract}

\section{Introduction}

Lot of work has been done on rare earth complex with oxygen ligands ${ }^{1-5}$. It is considered as important lasing material due to narrow line width \& weak crystal field interaction. Most $\mathrm{f} \leftrightarrow \mathrm{f}$ transitions in rare earths are found to be weak in comparison to one which are called as hypersensitive transition ${ }^{6-7}$. The intensity of hypersensitive transition changes with change of environment of metal ion in different complex ${ }^{8}$. Various intensity parameters i.e Judd-Ofelt parameters $\left(\mathrm{T}_{2}, \mathrm{~T}_{4}, \mathrm{~T}_{6}\right)$, bonding parameters $\mathrm{b}^{1 / 2}$, of complex ,energy parameters $\left(\mathrm{F}_{2}, \mathrm{~F}_{4}, \mathrm{~F}_{6}\right)$ \& covalency of complex have been calculated \& discussed as well.

\section{Experimental Details}

The complex of $\operatorname{Pr}^{3+}$ (Praseodymium chloride, proline \& propane 1,3-dio) was prepared ${ }^{9}$ $\&$ the chemicals used was of AR grade \& metals 99.9\%. Pure (Indian Rare earth Ltd.) were used. The complex was prepared in molar ratio 1:2:1. The visible spectra was recorded on model uv-2601 spectrophotometer (Rayleigh analytical instrument corp.) in 
the laboratory. Praseodymium ternary complex $\mathrm{ML}_{2} \mathrm{~L}^{\prime}$ with amino acid proline as primary ligand \& propane-1,3 diol as secondary ligand were prepared following Whan \& Cross by.

\section{Evaluation of Parameters}

$$
\mathrm{E}_{\mathrm{j}}\left(\mathrm{F}_{\mathrm{k}}, \zeta_{4 \mathrm{f}}\right)=\mathrm{E}_{\mathrm{oj}}\left(\mathrm{F}_{\mathrm{k}}^{0}, \zeta_{4 \mathrm{f}}^{0}\right)+\sum_{\mathrm{k}=2,4,6} \frac{\partial \mathrm{E}_{\mathrm{j}}}{\partial \mathrm{F}_{\mathrm{k}}} \Delta \mathrm{F}_{\mathrm{k}}+\frac{\partial \mathrm{E}_{\mathrm{j}}}{\partial \xi_{4 \mathrm{f}}} \Delta \zeta_{4 \mathrm{f}}
$$

Energy levels:- The energy levels for various transition were evaluated theoretically by using relation.

The observed energy ( have been converted into wave numbers ) as well as calculated values of energy levels using above equation for $\operatorname{Pr}^{3+}$ complex in different solvents has been collected in table-1. rms deviation calculated \& observed value is very low which actually supports the validity of relation. Some high value of rms deviation in case of $\mathrm{Pr}^{3+}$ complex supports the assumption of $4 \mathrm{f}-$ wave function to be hydrogenic ${ }^{10}$. From table-1. We find that the value of energy levels calculated for Praseodymium matches with observed value which clearly indicates that the formation of complex is perfect. The value of rms deviation is very small.

The calculated values of Slater-Condon parameters $\mathrm{F}_{2}, \mathrm{~F}_{4} \& \mathrm{~F}_{6}$, Racah parameters $\mathrm{E}^{1}, \mathrm{E}^{2}, \mathrm{E}^{3}$, Lande's parameters $\zeta_{4 \mathrm{f}}$, nephelauxetic ratio $\beta, \&$ bonding parameters $\mathrm{b}^{1 / 2}$ have been collected in table 2 . The decreases in value of $F_{2}$ from that of free ion may support the complexation. This decrease is bit more in case of $\operatorname{Pr}^{3+}$, which shows that on complexation the contraction of $4 \mathrm{f}$ - orbital is reduced ${ }^{11}$ with the increase in atomic number of metal ion.

The relation for nephelauxetic ratio $\beta \&$ degree of covalency $b^{1 / 2}$ is given by

$$
\mathrm{b}^{1 / 2}=\left[\frac{1-\beta}{2}\right]^{1 / 2}
$$

The value of Nephelauxetic ${ }^{11}$ ratio has been obtained using relation $\beta=\mathrm{F}_{2}{ }^{\mathrm{c}} / \mathrm{F}_{2}{ }^{\mathrm{f}}$ where subscript $\mathrm{c} \& \mathrm{f}$ refer to complex $\&$ free ion. The $\beta$ value for $\operatorname{Pr}^{3+}$ complex $<1.0$ shows that complex is covalent in nature. Also with change of metal i.e as the atomic number of metal ion increases the covalency decreases.

Intensity Parameter:- Oscillator strength of each transition has been calculation using the formula.

$$
\mathrm{P}_{\mathrm{exp}}=4.6 \times 10^{-9} \times \varepsilon_{\mathrm{m}} \times \Delta \ddot{\Downarrow}_{1 / 2}
$$

$\varepsilon_{\mathrm{m}} \& \Delta \ddot{y}_{1 / 2}$ are the molecular extinction coefficient $\&$ half band width respectively. 
Table 1:- observed \& calculation values of energy levels for $\mathrm{Pr}^{3+}$ complex in different solvents.

\begin{tabular}{|c|c|c|c|c|c|c|c|c|}
\hline \multirow[t]{2}{*}{ Levels } & \multicolumn{2}{|c|}{ water } & \multicolumn{2}{|c|}{ Methanol } & \multicolumn{2}{|l|}{ Ethanol } & \multicolumn{2}{|c|}{ Acetic Acid } \\
\hline & $\begin{array}{l}\text { Cal. } \\
\mathrm{cm}^{-1}\end{array}$ & $\begin{array}{l}\text { Obs. } \\
\mathrm{cm}^{-1}\end{array}$ & $\begin{array}{l}\text { Cal. } \\
\mathrm{cm}^{-1}\end{array}$ & $\begin{array}{l}\text { Obs. } \\
\mathrm{cm}^{-1}\end{array}$ & $\begin{array}{l}\text { Cal. } \\
\mathrm{cm}^{-1}\end{array}$ & $\begin{array}{l}\text { Obs. } \\
\mathrm{cm}^{-1}\end{array}$ & $\begin{array}{l}\text { Cal. } \\
\mathrm{cm}^{-1}\end{array}$ & $\begin{array}{l}\text { Obs. } \\
\mathrm{cm}^{-1}\end{array}$ \\
\hline${ }^{3} \mathrm{P}_{2}$ & 22406.76 & 22522 & 22342.42 & 22471 & 22337.93 & 22471 & 22353.13 & 22471 \\
\hline${ }^{3} \mathrm{P}_{1}$ & 21252.49 & 21367 & 21194.27 & 21321 & 21197.97 & 21321 & 21185.44 & 21321 \\
\hline${ }^{3} \mathrm{P}_{0}$ & 20789.78 & 20790 & 20745.71 & 20746 & 20763.37 & 20764 & 20703.54 & 20703 \\
\hline${ }^{1} \mathrm{D}_{2}$ & 17127.66 & 16977 & 17087.41 & 16920 & 17087.83 & 16920 & 17086.42 & 16920 \\
\hline \multicolumn{2}{|c|}{ rms deviation } & 110.7805 & \multicolumn{2}{|c|}{123.1064} & \multicolumn{2}{|c|}{123.5031} & \multicolumn{2}{|c|}{122.4382} \\
\hline
\end{tabular}

Table 2:- Computed value of Slater- Condon parameters \& Lande's parameters $\beta \& b^{1 / 2}$ for $\operatorname{Pr}^{3+}$ complex in different solvents.

\begin{tabular}{cllll}
\hline & Water & Methanol & Ethanol & Acetic Acid \\
\hline $\mathrm{F}_{2}\left(\mathrm{~cm}^{-1}\right)$ & 311.8876 & 311.4458 & 311.88 & 310.4087 \\
$\mathrm{~F}_{4}\left(\mathrm{~cm}^{-1}\right)$ & 43.0560 & 42.9951 & 43.0550 & 42.8519 \\
$\mathrm{~F}_{6}\left(\mathrm{~cm}^{-1}\right)$ & 4.7126 & 4.7059 & 4.7125 & 4.6902 \\
$\zeta_{4 \mathrm{f}}\left(\mathrm{cm}^{-1}\right)$ & 675.1093 & 668.2482 & 661.5235 & 684.3126 \\
$\mathrm{E}^{1}\left(\mathrm{~cm}^{-1}\right)$ & 4579.071 & 4572.586 & 4578.960 & 4557.358 \\
$\mathrm{E}^{2}\left(\mathrm{~cm}^{-1}\right)$ & 23.9529 & 23.9190 & 23.9523 & 23.8393 \\
$\mathrm{E}^{3}\left(\mathrm{~cm}^{-1}\right)$ & 462.9659 & 462.3102 & 462.9547 & 460.7707 \\
$\mathrm{~F}_{4} / \mathrm{F}_{2}$ & 0.13805 & 0.13805 & 0.13805 & 0.13805 \\
$\mathrm{~F}_{6} / \mathrm{F}_{2}$ & 0.01511 & 0.01511 & 0.01511 & 0.01511 \\
$\mathrm{E}^{1} / \mathrm{E}^{3}$ & 9.8907 & 9.8907 & 9.8907 & 9.8907 \\
$\mathrm{E}^{2} / \mathrm{E}^{3}$ & $5.1738 \mathrm{E}-02$ & $5.1738 \mathrm{E}-02$ & $5.1738 \mathrm{E}-02$ & $5.1738 \mathrm{E}-02$ \\
$\beta$ & 0.9683 & 0.9669 & 0.9683 & 0.9637 \\
$\mathrm{~b}^{1 / 2}$ & 0.1258 & 0.1285 & 0.1258 & 0.1346 \\
\hline
\end{tabular}

Free ion $\operatorname{Pr}^{3+} \mathrm{F}_{2}=322.09$ 
Table 3:- Observed \& calculated value of Oscillator strength for $\operatorname{Pr}^{3+}$ complex in different solvents.

\begin{tabular}{ccccccccc}
\hline Levels & \multicolumn{2}{c}{ water } & \multicolumn{3}{c}{ Methanol } & \multicolumn{2}{c}{ Ethanol } \\
& $\begin{array}{c}\text { Cal. } \\
\mathrm{x} 10^{-6}\end{array}$ & $\begin{array}{c}\text { Obs } \\
\mathrm{x} 10^{-6}\end{array}$ & $\begin{array}{c}\text { Cal. } \\
\mathrm{x} 10^{-6}\end{array}$ & $\begin{array}{c}\text { Obs. } \\
\mathrm{x} 10^{-6}\end{array}$ & $\begin{array}{c}\text { Cal. } \\
\mathrm{x} 10^{-6}\end{array}$ & $\begin{array}{c}\text { Obs. } \\
\mathrm{x} 10^{-6}\end{array}$ & $\begin{array}{c}\text { Cal. } \\
\mathrm{x} 10^{-6}\end{array}$ & $\begin{array}{c}\text { Obs. } \\
\mathrm{x} 10^{-6}\end{array}$ \\
\hline${ }^{3} \mathrm{P}_{2}$ & 12.1094 & 11.6616 & 10.0297 & 9.0269 & 10.3771 & 9.7665 & 10.4947 & 9.6195 \\
${ }^{3} \mathrm{P}_{1}$ & 5.7303 & 5.3054 & 5.4870 & 4.5356 & 5.1004 & 4.5210 & 4.6715 & 3.8410 \\
${ }^{3} \mathrm{P}_{0}$ & 2.5817 & 2.1691 & 2.8772 & 1.9514 & 2.6492 & 2.0855 & 3.2640 & 2.4576 \\
${ }^{1} \mathrm{D}_{2}$ & 3.6214 & 3.2842 & 2.9652 & 2.2102 & 3.0286 & 2.5688 & 2.7950 & 2.1360 \\
\hline
\end{tabular}

Table 4:- Compute value of $\mathrm{T}_{\lambda}$ - parameters $\& \mathrm{~T}_{4} / \mathrm{T}_{6}$ for $\operatorname{Pr}^{3+}$ complex in different solvents.

\begin{tabular}{lllll}
\hline & Water & Methanol & Ethanol & Acetic Acid \\
\hline $\mathrm{T}_{2} \times 10^{10}$ & 19.1646 & 5.6524 & -2.0128 & -64.9014 \\
$\mathrm{~T}_{4} \times 10^{10}$ & 7.2166 & 8.0259 & 7.3901 & 9.1238 \\
$\mathrm{~T}_{6} \times 10^{10}$ & 37.8427 & 30.7960 & 32.107 & 32.0301 \\
$\mathrm{~T}_{4} / \mathrm{T}_{6}$ & 0.1907 & 0.2606 & 0.2301 & 0.2848 \\
$\mathrm{rms}$ deviation & $4.0780 \mathrm{E}-07$ & $9.1353 \mathrm{E}-07$ & $5.5632 \mathrm{E}-07$ & $7.9695 \mathrm{E}-07$ \\
\hline
\end{tabular}

Table 5:- Refractive index value observed for Complex $\mathrm{Pr}^{3+}$ in different solvents.

\begin{tabular}{lll}
\hline Complex & Solvent & Refractive index \\
\hline \multirow{2}{*}{$\operatorname{Pr}(\mathrm{P})_{2} \mathrm{P}$} & water & 1.356 \\
& Methanol & 1.374 \\
& Ethanol & 1.382 \\
& Acetic Acid & 1.392 \\
\hline
\end{tabular}

Table 6:- Observed value of omega parameters complex $\operatorname{Pr}^{3+}$ in different solvents.

\begin{tabular}{ccccc}
\hline & Water & Methanol & Ethanol & Acetic Acid \\
\hline$\Omega_{2} \times 10^{20}$ & 13.1681 & 3.8365 & -1.3586 & -43.5066 \\
$\Omega_{4} \times 10^{20}$ & 4.9586 & 5.4474 & 4.9884 & 6.1161 \\
$\Omega_{6} \times 10^{20}$ & 2.6001 & 20.9023 & 21.6726 & 21.4714 \\
$\begin{array}{l}\text { Goodness of the } \\
\text { fit }\end{array}$ & 0.0375 & 0.1834 & 0.0673 & 0.1363 \\
\hline
\end{tabular}


In Fig. 1 We have show the variation of optical density with wavelength in all solvents for $\operatorname{Pr}^{3+}$ complex in visible region $(360-620 \mathrm{~nm})$. In figs $2-5$. A variation of optical density with wavelength in infrared region (1000-2000 $\mathrm{nm}$ ) have been shown for different solvents i.e water, methanol, ethanol, acetic acid.

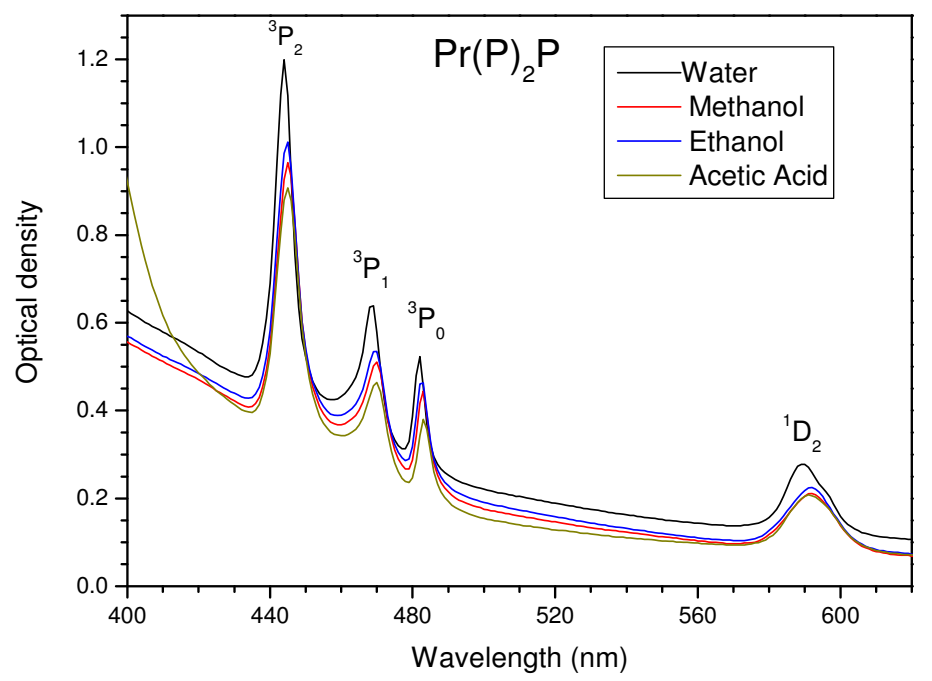

Fig. 1 Variation of optical density with wavelength for $\mathrm{Pr}^{3+}$ complex in different solvent.

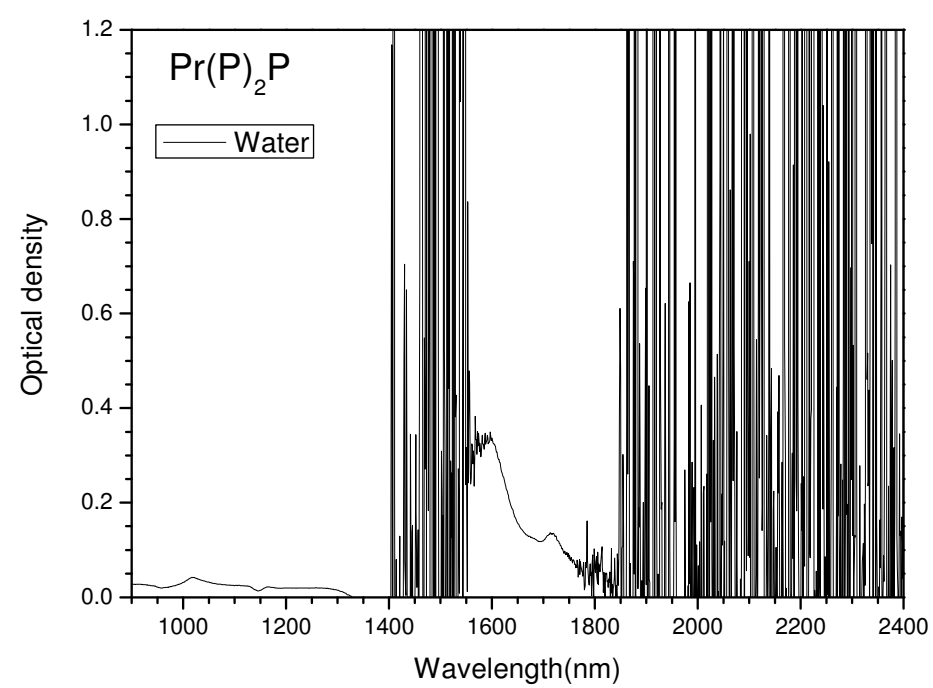

Fig. 2 A variation of optical density with wavelength in infrared region for water solvent. 


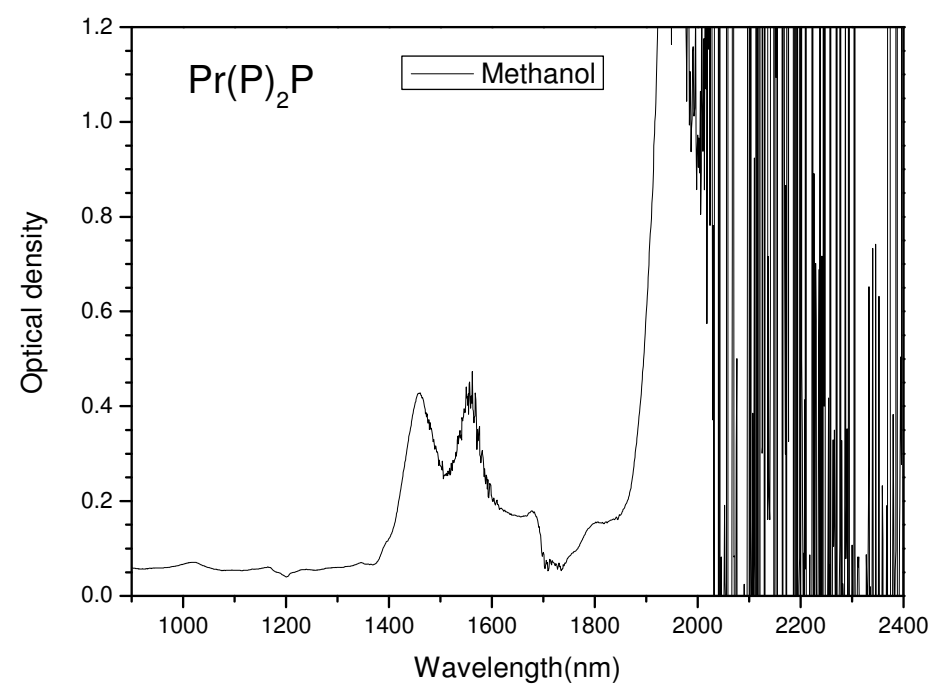

Fig. 3 A variation of optical density with wavelength in infrared region for methanol solvent.

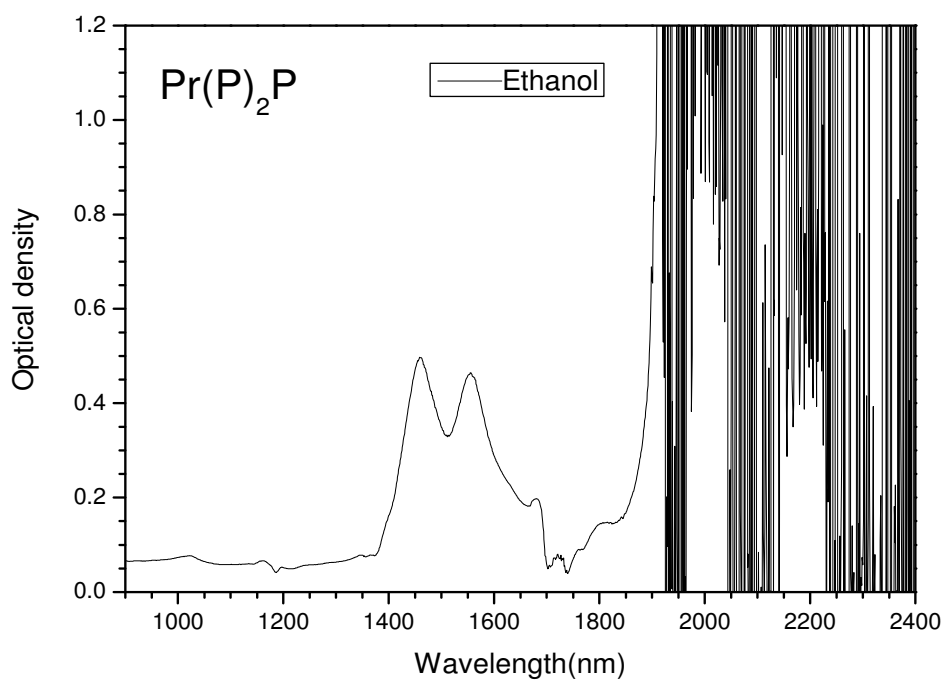

Fig. 4 A variation of optical density with wavelength in infrared region for ethanol solvent. 


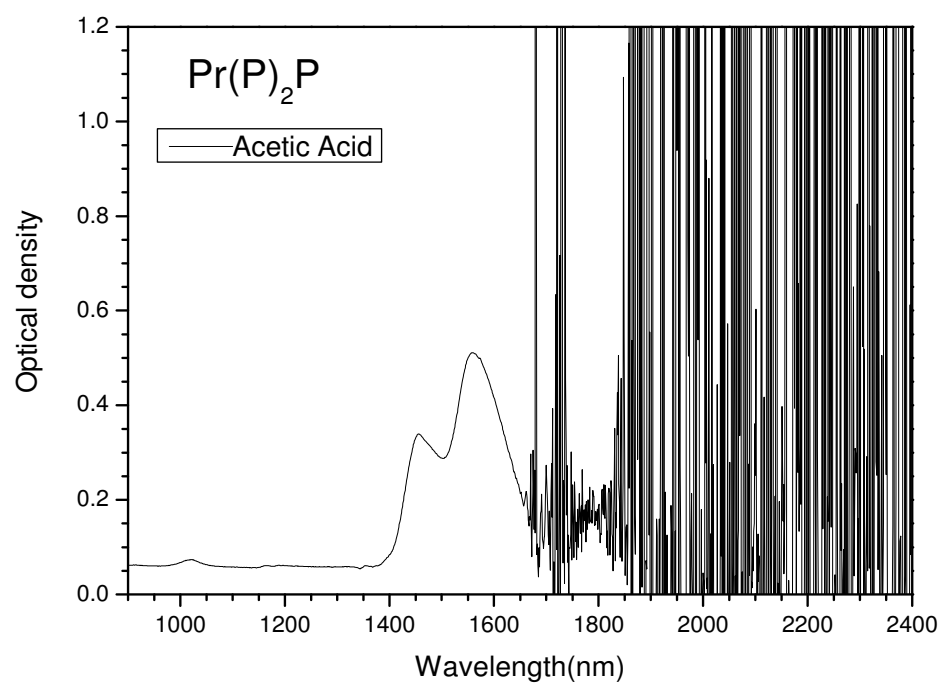

Fig. 5 A variation of optical density with wavelength in infrared region for acetic acid solvent.

\section{Results and Discussion}

The experimentally observed value of oscillator strength for $\operatorname{Pr}^{3+}$ complex along with their calculated value have been show in Table 3. The value of $F_{2}, F_{4} \& F_{6}$ parameter were computed using Judd-Ofelt relation ${ }^{12}$ by partial multiple regression method $\&$ have been collection in table-2. The value of reduced matrix elements were collected from Carnall et $\mathrm{al}^{13}$.

From Table 2- We have calculated the value of Slater-Condon parameters $F_{2}$ in different solvent $\&$ the value matches with free ion value. In Table 3- We have reported the calculated value of Oscillator strength for $\operatorname{Pr}^{3+}$ complex in different solvents which is in good agreement with observed value.

From table- 4 we have observed that value of $\mathrm{T}_{4} \& \mathrm{~T}_{6}$ remain nearly invariant. It has been observed that the value of $\mathrm{T}_{2}$ changes linearly with molecular weight of amino acid. In case of $\mathrm{Pr}^{3+}$ complex $\mathrm{T}_{2}$ is negative which has no physical significance . From above table we observe that the ratio of $\mathrm{T}_{4} / \mathrm{T}_{6}$ is low in $\mathrm{Pr}^{3+}$ complex. The complex under study have ratio $\left(\mathrm{T}_{4} / \mathrm{T}_{6}\right)$ lies between $0.19-0.28$ supporting that they have oxygen / nitrogen -donor liquids. Also in table-4 $\mathrm{We}$ have reported $\mathrm{T}_{\lambda}$ parameters low value of $\mathrm{rms}$ deviation confirms the formation of complex. Four peaks have been observed in case of $\mathrm{Pr}^{3+}$ complex. Also in case of $\mathrm{Pr}^{3+}$ complex we have pseudo- hypersensitive transition $\left({ }^{3} \mathrm{H}_{4} \rightarrow{ }^{3} \mathrm{P}_{2}\right)$, not much shifting of peak even when the solvents were changed.

The difference of energy value between observed \& calculated is very small supports the formation of complex well. The value of refractive index have also been obtained which are in order.

Water-1.356, Methanol- 1.374, Ethanol- 1.382, Acetic Acid- 1.392 
In Table-5. We have reported the value of refractive index for $\operatorname{Pr}^{3+}$ complex which is in the increasing order as is the increasing order of molecular weight of the solvents. In Table-6. We have reported the value of omega parameters for $\mathrm{Pr}^{3+}$ in different solvents.

For $\mathrm{Pr}^{3+}$ the value of oscillator strength is max. for pseudo- hypersensitive transition. The variation of wave length with optical density for $\operatorname{Pr}^{3+}$ complex has been shown in graph in visible region. We have also shown the Infra-red spectra in range 1000-2000 nm for $\operatorname{Pr}^{3+}$ complex in graph in all solvents, observed is almost same in all solvents. Both the complex have been show in single graph in different solvent indicating that peaks are almost in same position but intensity is changing.

\section{Acknowledgment}

One of the author Shri Kishan Ujjwal thanks UGC, New Delhi for awarding Rajiv Gandhi National Fellowship.

\section{References}

1. R D Peacock, Struct \& Bonding ( Germany). 22, 83(1975)

2. S P Tandon \& P C Mehta, J.Chem Phys. (USA),52 , 4313(1970)

3. D G Karakker ,J.inorg \& Nucl chem (GB),33, 3713 (1971)

4. Y K Sharma,SSL Surana,R P Dubedi,Mat.Sci.Engg.B,119,131 (2005)

5. Y K Sharma,SSL Surana,Optical Materials,29,598 (2007)

6. W Streak, Theor Chim Acta (Berlin), 52, 45 (1979).

7. M P Bhutra \& Anup K.Gupta, Ind. J. Pure \& Appl Phys 20,954 (1982)

8. B R Judd,Phys Rev.(USA),127, 750 (1962)

9. G S Ofelt, J. Chem Phys.(USA),37, 511 (1962)

10. S N Mishra,G K Joshi,M P Bhutra,Ind.Journal of chem sci. 21, 275 (1982)

11. S P Tandon, R C Govil, Spectroscopic letters (USA),6, 125 (1973)

12. Cyril H Goulden, Method of statistical analysis (Asia Publishing House, Bombay,1964).

13. W T Carnall, P R Fields \& B G Wybourne, J Chem .Phys (USA) 42, 3797 (1965)

14. R E Whan \& C A Crossby, J.Mole.Spec. (USA), 8, 315 (1962) 